\title{
AN EMPIRICAL STUDY ON DISCUSSION AND EVALUATION OF GREEN UNIVERSITY
}

\begin{abstract}
Sustainable development has become an important criterion for human beings to pursue happiness in their daily lives. In order to ensure the sustainable development of the earth, the first step is to let this concept take root. Hence, the key to making a campus into a green university and promoting national consensus lies in the implementation quality. Moreover, the influence of the factors can be effectively examined and improved by providing correction plans on a rolling basis according to the green university certification criteria and from the perspective of business performance. The aim is to provide detailed coping strategies and facilitate schools moving towards the goal of a green university. By the Decision Making Trial and Evaluation Laboratory (DEMATEL), this study explored the criteria for green university evaluation, investigated the causal relationship and mutual influence among criteria. It also offered suggestions on green performance management for the case university. The findings of this study can help schools to develop environmental policies, identify the priorities for implementing green university policies, and achieve the goal of a green university efficiently.
\end{abstract}

Keywords: green university, green university policies, Decision Making Trial and Evaluation Laboratory (DEMATEL), evaluation criteria, sustainability

\section{Introduction}

With the rapid development of social and economic activities due to technological progress, life and consumption patterns have changed into a model of mass manufacturing, mass consumption, and mass abandonment, which causes environmental pollution, sharply decreases resources, and endangers the sustainable development of humankind. Economic development has damaged the global environment and resources, and such environmental deterioration has destroyed economic development. In order to improve the global environment, Sustainable Development (SD), which is defined as "meeting the needs of the present generation without damaging the well-being of future generations", has become a way to address this dilemma and seek human well-being [1,2]. As campuses are places for the inheritance of knowledge and culture, the "sustainable campus" is a product of the ideological global trend of "sustainable development". Enhancing human environmental awareness is conducive to the improvement of environmental systems and the promotion of environmental management [3].

Accordingly, in order to achieve the goal of sustainable development, the Ministry of Education (Taiwan) has promoted sustainable campuses in primary and secondary schools since 1998. The Ministry of Education (Taiwan) subsidized more than 10 public and private universities in 2004 to establish sustainable university campus demonstration bases, which

\footnotetext{
${ }^{1}$ Institute of Service Industries and Management, Minghsin University of Science and Technology, Hsinchu 30401, Taiwan, email: chiahuei530@gmail.com
} 
have become the forerunners of the green university movement in Taiwan. The green university development program was launched in 2007, which is dedicated to promoting the concept of green universities and hopes to integrate the concepts of sustainable development and environmental protection into university education, in order to give full play to the function of university education.

The green university criteria are one of the tools to help universities move towards sustainable development and have comprehensive understanding of their own situations. Hence, the effective use of resources can be achieved by understanding the criteria that determines their relationships and changes, identifies core criteria, and provides limited resources for schools to invest in key influence criteria [4, 5].

The research purposes are as follows: 1) to explore green university evaluation criteria by DEMATEL; 2) to investigate the causal relationship and mutual influence among criteria; 3 ) to offer suggestions on green performance management for the case university.

\section{Literature review}

\section{Green university}

Globally, the common meaning of the term "green university" refers to the various activities of universities with the concept of "sustainable development" as the vision, and the important responsibilities taken by universities for the development of society as the representatives of the higher education. This concept was initially developed in North America in 1970 to reduce the impact of environmental problems on campuses and communities, where early green universities focused on the most basic problems, and university environmental movements emerged in response to these environmental problems $[6,7]$.

Green university-related studies and practical experience cover a wide range of issues, including university management, planning, development, education, research, operations, community services, procurement, transportation, design, new construction, and renovation [8]. Basically, the business strategy of a green university still focuses on "sustainable development", and has the goals of constructing or adjusting facilities to be environmentally friendly enterprises from the perspective of function, developing basic rules and declarations, establishing new specific institutions, and guiding the main tasks and management of the universities in the direction of sustainable development. In brief, the vision of a green university is sustainable development. Universities can set certain objectives based on this vision and formulate complex implementation strategies and action plans based on each objective. The premise of all goals and strategies is to build sustainable universities, in order to realize the ideal of sustainable development [8].

The concept of the "green university" was initially developed to reduce the negative environmental impact of university operations. In particular, universities with large campuses and a high number of students will produce a large amount of waste water, chemicals, and toxic waste during operation, and may consume more resources than simple communities or corporate groups [9]. As such materials will eventually become environmental problems for campuses and surrounding communities, how to reduce the impact of these problems on campuses and communities is the basic problem to be solved by early green universities. Moreover, the business strategy of green universities still focuses on "sustainable development", with the goal of constructing or adjusting universities to be environmentally friendly enterprises from the perspective of function, 
developing basic rules and declarations, establishing new specific institutions, and guiding the main tasks and management of the universities in the direction of sustainable development.

Overall, the development of green universities started with various management strategies to protect the environment, and then, gradually extended to the development of environmental education to enhance people's environmental awareness, thus, integrating the idea of sustainable development and environmental protection into university education and giving full play to the function of university education [10]. In addition, universities must constantly examine their internal business management and external environment, develop improvement strategies and action plans, reduce their impact on the environment, and ultimately, give back to the surrounding communities and society.

\section{Green university evaluation criteria}

While the concept of environmental sustainable development has reached global maturity, few studies have focused on "green university" or "sustainable university", which has gradually become the focus of experts and scholars in various fields in recent years. Through expert interviews and a questionnaire survey, they constructed 3 major aspects for the green university evaluation criteria system, namely, environmental management, environmental system, and environmental education, with 12 primary criteria and 51 secondary criteria. Through numerous expert interviews and 2 rounds of a Delphi expert questionnaire survey regarding criteria revision [10]. A study summarized and constructed 3 major aspects of the green university evaluation criteria system, namely, environmental management, environmental system, and environmental education, with 15 primary criteria and 44 secondary criteria [11]. The study continued the green university criteria structure, as developed from 2002 to 2005 , to further refine the criteria structure, and quantified the criteria as an evaluation tool for a specific evaluation method. Through an expert symposium and a Delphi expert questionnaire survey, the finalized criteria structure included 3 major aspects, namely, environmental system, environmental management, and environmental education, with 13 primary criteria and 37 secondary criteria. In order to understand the correlation among environmental cognition, environmental attitudes, and environmental behaviours of college students [12]. Previous researchers examined the relationships among environmental cognition, attitudes, and behaviours of undergraduates' environmental concepts. Further, the confirmatory factor analysis (CFA) of linear structural equation modelling (SEM) method was employed to check the relationships. The study framework was developed base on a balanced scorecard. Then the green university criteria were constructed by literature review, expert interview, and practical survey [13, 14].

According to the above studies on green universities, green university evaluation criteria have been effectively constructed in academic circles since last 10 years; however, the above discussions show that there are 2 deficiencies in previous studies regarding green university evaluation. First, most of the studies assumed that the evaluation criteria were independent of each other, meaning without mutual influence and causal relationships. Second, some studies assumed that the evaluation criteria had the same weights, which actually limited further study of green university evaluations. In order to actually help universities invest limited resources in key criteria and achieve the goal of a green university, this study argues that universities must understand the relationship among criteria, clarify the nature of problems, and identify the core criteria. 
According to the above literature review and the viewpoint of this study, this study developed 3 dimensions and 10 evaluation criteria for a green university. Please refer to Table 1 for the details.

- Environmental system: campus air quality, smoke pollution control on campus, green transport planning, and base greening.

- Environmental management: waste classification, resource recovery, and energy conservation.

- Environmental education: sustainability-related studies, in-depth environmental education, and green university certification.

Table 1

Green university evaluation criteria

\begin{tabular}{|l|l|}
\hline \multicolumn{1}{|c|}{ Dimension } & \multicolumn{1}{c|}{ Evaluation criteria } \\
\hline \multirow{4}{*}{ Environmental system } & a. campus air quality \\
\cline { 2 - 2 } & b. smoke pollution control on campus \\
\cline { 2 - 2 } & c. green transport planning \\
\cline { 2 - 2 } Environmental management & d. base greening \\
\cline { 2 - 2 } & e. waste classification \\
\cline { 2 - 2 } Environmental education & f. resource recovery \\
\cline { 2 - 2 } & g. energy conservation \\
\cline { 2 - 2 } & h. sustainability-related studies \\
\cline { 2 - 2 } & i. in-depth environmental education \\
\cline { 2 - 2 } & j. green university certification \\
\hline
\end{tabular}

\section{Research method}

\section{Decision Making Trial and Evaluation Laboratory}

Developed by the Battelle Memorial Institute of the Graduate Institute in Geneva. DEMATEL is used to study complex global problems, such as race, hunger, environmental protection, energy, etc. [15]. By directly comparing the relationships among variables in a complex system, the main purpose of this method is to solve the direct and indirect causal relationships of the issues to assist in decision making, determine the strength of influence among all variables through matrix operations, and particularly, express the causal relationships and influence among the variables in a complex system with a visual structure matrix and a cause-and-effect diagram. In other words, DEMATEL can convert complex systems into clearly structured causal relationships, that is, the relationships among variables in a complex system are simplified into two groups of cause and effect, which can help identify the core problems in a complex system and provide improvement directions by qualifying the influence among variables.

Due to the uncertain factors existing in human decision management activities, appropriate methods can be chosen according to the characteristics of problems when the nature of the problems is discussed in depth. Modelling is a common method for social and biological systems, which are often difficult to express by mathematical models. In order to reflect the essential characteristics and evolutionary trends of a system, DEMATEL determines the interdependency and restrictions among variables according to the specific characteristics of the objective issues by modelling $[15,16]$.

By directly comparing the relationships among factor characteristics in a complex system, the main purpose of DEMATEL is to solve the causal relationships and determine 
the influential strengths among all variables through matrix operations. A direct-relation diagram can illustrate the influence among all elements in a system, with the figures showing the strength of such influence, as shown in Figure 1. Moreover, a cause-and-effect diagram is used for structuring complex problems and dividing all criteria into the two categories of cause and effect, helping to identify the core problems in a complex system, and determining the improvement directions according to the influence among the quantified quality characteristics [17].

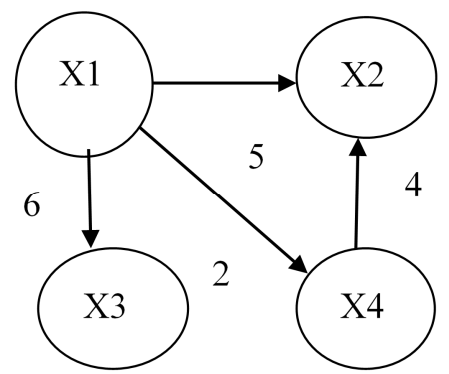

Fig. 1. Direct-relation diagram of DEMATEL

In recent years, DEMATEL has been widely used to solve problems in various fields. $\mathrm{Wu}$ and Lee [18] developed the core capabilities of managers by Fuzzy DEMATEL. Lin and Wu [19] used Fuzzy DEMATEL in group decision-making. Lee and Hsieh [20] employed DEMATEL to analyse the causality between service attributes to adjust the importance of service attributes and resolve core problems. Wu [21] explored the core implementation and core issues in knowledge management by Fuzzy DEMATEL. Guo and Tsai [22] evaluated Green Supply Chain Suppliers. Tsai and Wang [23] evaluated the performance of human resources in green logistics enterprises.

\section{Operational steps}

This study summarizes the operational steps of DEMATEL, as follows:

First, the quality characteristics influencing a complex system are listed according to expert opinions, and a measurement scale of the influence among the quality characteristics is established; for example: very high $=4$, high $=3$, low $=2$, very low $=1$, no influence $=0$.

When the number of quality characteristic is $n$, the influence and its degree among quality characteristics are established through expert opinions, in order to obtain the directrelation matrix $X$ of $n \times n$. In the direct-relation matrix $X, X_{i j}$ represents the degree to which quality characteristic $i$ influences quality characteristic $j$, and the diagonal quality characteristic of the direct-relation matrix $X$ is set to 0 .

$$
X=\left[\begin{array}{cccc}
0 & x_{12} & \cdots & x_{1 n} \\
x_{21} & 0 & \cdots & x_{2 n} \\
\vdots & \vdots & \ddots & \vdots \\
x_{n 1} & x_{n 2} & \cdots & 0
\end{array}\right]
$$


The normalized direct-relation matrix is calculated based on the column vectors and the maximum. Let $\lambda=1 / \max _{1 \leq i \leq n}\left(\sum_{j=1}^{n} x_{i j}\right)$, and multiply the direct-relation matrix $X$ by $\lambda$ to obtain the normalized direct-relation matrix $N$, then:

$$
N=\lambda X
$$

$T$ is the total-relation matrix, and Eq. (3) is used to obtain:

$$
T=\lim _{k \rightarrow \infty}\left(N+N^{2}+\cdots+N^{k}\right)=N(I-N)^{-1}
$$

where $I$ is the identity matrix.

Let $t_{i j}$ be the quality characteristic in total-relation matrix $T$, where $i, j=1,2, \ldots, n$. Calculate the sum of the columns and rows in total-relation matrix $T$. $D_{i}$ is the sum of column $i$, and represents the sum of the influence given to other quality characteristics, and quality characteristic $i$ is the cause; $R_{j}$ is the sum of row $j$, and represents the sum of the influence received by other quality characteristics, and quality characteristic $i$ is the result. The sum of the rows and the sum of the columns are separately denoted as vector $D$ and vector $R$ in Eqs. (4) and (5):

$$
\begin{aligned}
& D_{i}=\sum_{j=1}^{n} t_{i j} \quad(i=1,2, \ldots, n) \\
& R_{j}=\sum_{i=1}^{n} t_{i j} \quad(j=1,2, \ldots, n)
\end{aligned}
$$

$\left(D_{i}+R_{j}\right)$ is defined as the prominence, where $t=i=j=1,2, \ldots, n$, and represents the total influence given to and received by the quality characteristic, which can show the core degree of quality characteristic $t$ in all problems. $\left(D_{i}+R_{j}\right)$ is defined as the relation, and represents the difference of the influence given to and received by the quality characteristic, which can show the causality degree of an attribute on quality characteristic $t$ in all problems. If it is positive, the quality characteristic tends to be the cause; if it is negative, the quality characteristic tends to be the result. Hence, decision-makers can determine the core driving factors according to the causal relationship and mutual influence among quality characteristics, and make appropriate decisions to solve problems according to their categories and influences.

\section{Research results and discussion}

\section{Questionnaire design}

In this study, the Minghsin University of Science and Technology, Taiwan was taken as the target, and the questionnaires were issued from March 1 to March 20, 2019. Experts were invited to give advice on the green university evaluation criteria. A 7-point scale was used for measurement, ranging from 6 (the greatest influence) to 0 (no influence), and the intermediate scores were given according to importance. A total of 15 experts were surveyed, including 9 professors and 6 university administrators. The author visited all experts in person to explain the questionnaire, and then, asked them to answer. A total of 15 formal questionnaires were issued, and 15 valid questionnaires were collected, for an effective recovery rate of $100 \%$. 
This study proposes 3 dimensions and 10 evaluation criteria for green university evaluation; refer to the above-mentioned Table 1 for details. "Environmental system" includes campus air quality, smoke pollution control on campus, green transport planning, and base greening. "Environmental management" includes waste classification, resource recovery, and energy conservation. "Environmental education" includes sustainability-related studies, in-depth environmental education, and green university certification.

\section{Research results and discussion}

Table 2 shows the survey results of expert opinions. The scores of the 15 experts are averaged to one decimal place to obtain a 10-criteria questionnaire. There are 100 squares in total, after the influence 0 given by 10 diagonal criteria are deducted, a total of 90 mutual influences are obtained. Please refer to Table 2 for details.

Table 2

The initial direct-relation Matrix $X$

\begin{tabular}{|c|c|c|c|c|c|c|c|c|c|c|}
\hline Criteria & $\boldsymbol{a}$ & $\boldsymbol{b}$ & $\boldsymbol{c}$ & $\boldsymbol{d}$ & $\boldsymbol{e}$ & $\boldsymbol{f}$ & $\boldsymbol{g}$ & $\boldsymbol{h}$ & $\boldsymbol{i}$ & $\boldsymbol{j}$ \\
\hline $\boldsymbol{a}$ & 0.0 & 1.2 & 1.4 & 0.8 & 0.5 & 0.4 & 0.3 & 0.7 & 2.1 & 2.5 \\
\hline $\boldsymbol{b}$ & 3.2 & 0.0 & 1.1 & 1.5 & 0.7 & 1.8 & 1.2 & 2.1 & 1.6 & 1.5 \\
\hline $\boldsymbol{c}$ & 2.9 & 0.3 & 0.0 & 0.9 & 0.8 & 1.8 & 2.7 & 2.4 & 1.7 & 2.3 \\
\hline $\boldsymbol{d}$ & 3.1 & 1.9 & 2.2 & 0.0 & 1.4 & 0.9 & 2.3 & 2.2 & 3.4 & 5.2 \\
\hline $\boldsymbol{e}$ & 0.7 & 0.9 & 1.5 & 1.2 & 0.0 & 3.7 & 1.5 & 2.3 & 1.8 & 2.6 \\
\hline $\boldsymbol{f}$ & 1.2 & 1.3 & 1.3 & 1.5 & 2.3 & 0.0 & 1.7 & 1.8 & 2.0 & 2.7 \\
\hline $\boldsymbol{g}$ & 1.1 & 0.8 & 1.5 & 1.6 & 2.7 & 3.2 & 0.0 & 3.7 & 3.1 & 5.5 \\
\hline $\boldsymbol{h}$ & 1.3 & 0.9 & 0.8 & 2.3 & 2.3 & 2.8 & 2.7 & 0.0 & 3.2 & 3.4 \\
\hline $\boldsymbol{i}$ & 1.8 & 1.6 & 2.3 & 3.9 & 3.5 & 4.5 & 4.6 & 3.9 & 0.0 & 5.6 \\
\hline $\boldsymbol{j}$ & 0.6 & 0.5 & 0.4 & 1.9 & 2.1 & 2.2 & 2.5 & 3.1 & 3.8 & 0.0 \\
\hline
\end{tabular}

Then, the normalized direct-relation matrix is calculated based on the column vectors and the maximum, and the inverse of the maximum of all column sums is $\lambda$. According to Eq. (2), the direct-relation matrix $X$ is multiplied by $\lambda$ to obtain the normalized direct-relation matrix $N$, and the influence coefficient is rounded to two decimal places. Please refer to Table 3.

The normalized direct-relation Matrix $T$

Table 3

\begin{tabular}{|c|c|c|c|c|c|c|c|c|c|c|}
\hline Criteria & $\boldsymbol{a}$ & $\boldsymbol{b}$ & $\boldsymbol{c}$ & $\boldsymbol{d}$ & $\boldsymbol{e}$ & $\boldsymbol{f}$ & $\boldsymbol{g}$ & $\boldsymbol{h}$ & $\boldsymbol{i}$ & $\boldsymbol{j}$ \\
\hline $\boldsymbol{a}$ & 0.00 & 0.04 & 0.04 & 0.03 & 0.02 & 0.01 & 0.01 & 0.02 & 0.07 & 0.08 \\
\hline $\boldsymbol{b}$ & 0.10 & 0.00 & 0.03 & 0.05 & 0.02 & 0.06 & 0.04 & 0.07 & 0.05 & 0.05 \\
\hline $\boldsymbol{c}$ & 0.09 & 0.01 & 0.00 & 0.03 & 0.03 & 0.06 & 0.09 & 0.08 & 0.05 & 0.07 \\
\hline $\boldsymbol{d}$ & 0.10 & 0.06 & 0.07 & 0.00 & 0.04 & 0.03 & 0.07 & 0.07 & 0.11 & 0.16 \\
\hline $\boldsymbol{e}$ & 0.02 & 0.03 & 0.05 & 0.04 & 0.00 & 0.12 & 0.05 & 0.07 & 0.06 & 0.08 \\
\hline $\boldsymbol{f}$ & 0.04 & 0.04 & 0.04 & 0.05 & 0.07 & 0.00 & 0.05 & 0.06 & 0.06 & 0.09 \\
\hline $\boldsymbol{g}$ & 0.03 & 0.03 & 0.05 & 0.05 & 0.09 & 0.10 & 0.00 & 0.12 & 0.10 & 0.17 \\
\hline $\boldsymbol{h}$ & 0.04 & 0.03 & 0.03 & 0.07 & 0.07 & 0.09 & 0.09 & 0.00 & 0.10 & 0.11 \\
\hline $\boldsymbol{i}$ & 0.06 & 0.05 & 0.07 & 0.12 & 0.11 & 0.14 & 0.15 & 0.12 & 0.00 & 0.18 \\
\hline $\boldsymbol{j}$ & 0.02 & 0.02 & 0.01 & 0.06 & 0.07 & 0.07 & 0.08 & 0.10 & 0.12 & 0.00 \\
\hline
\end{tabular}

Then, Eq. (2) and Eq. (3) are used to calculate the total-relation matrix $T$. The total-relation criteria matrix is acquired in Table 4. 
The total-relation criteria matrix $T_{C}$

\begin{tabular}{|c|c|c|c|c|c|c|c|c|c|c|c|}
\hline Criteria & $\boldsymbol{a}$ & $\boldsymbol{b}$ & $\boldsymbol{c}$ & $\boldsymbol{d}$ & $\boldsymbol{e}$ & $\boldsymbol{f}$ & $\boldsymbol{g}$ & $\boldsymbol{h}$ & $\boldsymbol{i}$ & $\boldsymbol{j}$ & $\boldsymbol{D}$ \\
\hline $\boldsymbol{a}$ & 0.04 & 0.06 & 0.08 & 0.07 & 0.06 & 0.07 & 0.07 & 0.09 & 0.13 & 0.16 & 0.83 \\
\hline $\boldsymbol{b}$ & 0.15 & 0.04 & 0.08 & 0.11 & 0.09 & 0.13 & 0.11 & 0.15 & 0.14 & 0.16 & 1.15 \\
\hline $\boldsymbol{c}$ & 0.14 & 0.05 & 0.05 & 0.10 & 0.10 & 0.15 & 0.16 & 0.17 & 0.15 & 0.20 & 1.26 \\
\hline $\boldsymbol{d}$ & 0.18 & 0.11 & 0.14 & 0.10 & 0.15 & 0.16 & 0.19 & 0.20 & 0.24 & 0.33 & 1.80 \\
\hline $\boldsymbol{e}$ & 0.08 & 0.07 & 0.10 & 0.11 & 0.08 & 0.20 & 0.13 & 0.17 & 0.16 & 0.21 & 1.31 \\
\hline $\boldsymbol{f}$ & 0.10 & 0.08 & 0.09 & 0.12 & 0.14 & 0.10 & 0.14 & 0.15 & 0.16 & 0.21 & 1.28 \\
\hline $\boldsymbol{g}$ & 0.12 & 0.08 & 0.12 & 0.15 & 0.19 & 0.23 & 0.13 & 0.25 & 0.24 & 0.35 & 1.87 \\
\hline $\boldsymbol{h}$ & 0.11 & 0.08 & 0.09 & 0.16 & 0.17 & 0.20 & 0.19 & 0.13 & 0.22 & 0.27 & 1.63 \\
\hline $\boldsymbol{i}$ & 0.17 & 0.13 & 0.17 & 0.25 & 0.25 & 0.31 & 0.30 & 0.30 & 0.20 & 0.41 & 2.48 \\
\hline $\boldsymbol{j}$ & 0.09 & 0.06 & 0.08 & 0.14 & 0.16 & 0.18 & 0.18 & 0.21 & 0.23 & 0.16 & 1.48 \\
\hline $\boldsymbol{R}$ & 1.17 & 0.76 & 0.99 & 1.31 & 1.39 & 1.74 & 1.61 & 1.80 & 1.85 & 2.46 & \\
\hline
\end{tabular}

According to Eq. (4) and Eq. (5), $D_{i}$ of each column and $R_{j}$ of each row can be calculated, and prominence $(D+R)$ and relation $(D-R)$ can be obtained. The total influence given and received on the dimensions and criteria is summarized in Table 5. Moreover, the 10 criteria can be drawn as Figure 2, with prominence as the horizontal axis and relation as the vertical axis.

Table 5

Summary of DEMATEL prominence and relation

\begin{tabular}{|c|c|c|c|c|}
\hline Criteria & $\boldsymbol{D}$ & $\boldsymbol{R}$ & $\boldsymbol{D}+\boldsymbol{R}$ & $\boldsymbol{D}-\boldsymbol{R}$ \\
\hline $\boldsymbol{a}$ & 0.83 & 1.17 & 2.00 & -0.35 \\
\hline $\boldsymbol{b}$ & 1.15 & 0.76 & 1.92 & 0.39 \\
\hline $\boldsymbol{c}$ & 1.26 & 0.99 & 2.25 & 0.28 \\
\hline $\boldsymbol{d}$ & 1.80 & 1.31 & 3.11 & 0.49 \\
\hline $\boldsymbol{e}$ & 1.31 & 1.39 & 2.70 & -0.09 \\
\hline $\boldsymbol{g}$ & 1.28 & 1.74 & 3.02 & -0.46 \\
\hline $\boldsymbol{h}$ & 1.87 & 1.61 & 3.48 & 0.26 \\
\hline $\boldsymbol{i}$ & 1.63 & 1.80 & 3.43 & -0.17 \\
\hline $\boldsymbol{j}$ & 2.48 & 1.85 & 4.33 & 0.63 \\
\hline Mean value & 1.48 & 2.46 & 3.94 & -0.99 \\
\hline
\end{tabular}

According to the analysis results, as shown in Table 5 and Figure 2, the causal relationship and mutual influence among the 10 green university evaluation criteria are explained, as follows:

- High relation and high prominence: there are 3 criteria, namely, $d$ "base greening", $g$ "energy conservation" and $i$ "in-depth environmental education". Categorized as causes, the 3 criteria are the core items influencing other attributes, indicating that they are the driving factors to solve problems.

- High relation and low prominence: there are 2 criteria, namely, $b$ "smoke pollution control on campus" and $c$ "green transport planning". The 2 criteria have little influence on a few other attributes, indicating that these attributes are relatively independent.

- Low relation and high prominence: there are 4 criteria, namely, $e$ "waste classification", $f$ "resource recovery", $h$ "sustainability-related studies", and $j$ "green university certification". These 4 criteria are categorized as results and are influenced by other 
attributes. While these attributes require improvements, they cannot be directly improved, as they are the attributes categorized as results.

- Low relation and low prominence: there is only 1 criterion, namely, a "campus air quality". This criterion is less influenced by other attributes, indicating that this attribute is relatively independent.

Overall, in the 10 green university evaluation criteria, the 3 attributes of $d$ "base greening", $g$ "energy conservation", and $i$ "in-depth environmental education", have high relation and high prominence, and thus, are the core items influencing other attributes. These 3 attributes can be improved to solve a core problem and improve the performance and competitiveness of other attributes.

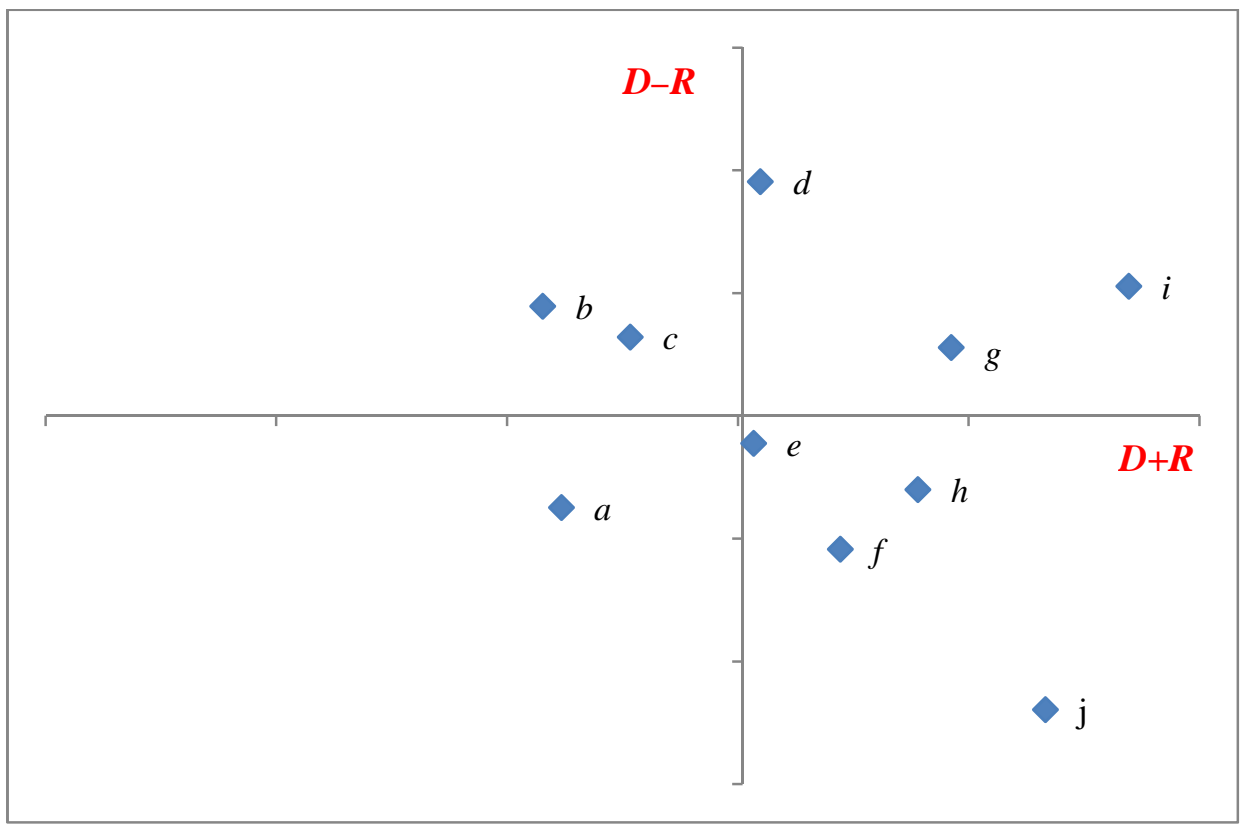

Fig. 2. Mutual influence among 10 criteria

\section{Conclusion}

The development of green universities started with various management strategies to protect the environment, and then, gradually extended to the development of environmental education to enhance people's environmental awareness, in order to integrate the concepts of sustainable development and environmental protection into university education and give full play to the function of university education. In addition, universities shall constantly examine their internal business management policies and external environment, develop improvement strategies and action plans, reduce their impact on the environment, and give back to communities and society.

This study first explored green university evaluation criteria by DEMATEL, and then, investigated the causal relationships and mutual influences among the criteria. Finally, suggestions are proposed for the green performance management of the case university. 
Overall, in the 10 green university evaluation criteria, the 3 attributes of $d$ "base greening", $g$ "energy conservation", and $i$ "in-depth environmental education", have high relation and high prominence, and thus, are the core items influencing other attributes. These 3 attributes can be improved to solve a core problem and improve the performance and competitiveness of other attributes.

By understanding the criteria, determining their relationships and changes, identifying the core criteria, and providing limited resources for schools to invest in key influential criteria, the effective use of resources can be achieved. Hence, it is suggested that, in order to enhance its performance as a green university, the case university should take the initiative to start university base greening, encourage energy conservation, and improve environmental education.

\section{Research limitations}

Most studies assumed that evaluation criteria were independent of each other, meaning without mutual influence or a causal relationship; however, such evaluation criteria may actually influence each other, and the influence may be complex. In order to solve this problem, and address the main problem factors, this study directly compared the relationships among criteria, and determined the causal relationships and the influential strengths among all factors through the matrix operations of Fuzzy DEMATEL. Then, according to the results, limited resources can be applied to solve the most important problems first. It is suggested that future researchers can develop other green university evaluation criteria systems by other evaluation models, and then, comprehensively compare the differences of various evaluation models.

\section{References}

[1] Mamoudou C. Determinants of production-based and consumption-based $\mathrm{CO}_{2}$ emissions: a comparative analysis. Int J Environ Pollut. 2020;67(1):22-47. DOI: 10.1504/IJEP.2020.108362.

[2] Marszałek M, Kowalski Z, Makara A. The possibility of contamination of water-soil environment as a result of the use of pig slurry. Ecol Chem Eng S. 2019;26(2):313-30. DOI: 10.1515/eces-2019-0022.

[3] Suwartha N, Sari RF. Evaluating UI Green Metric as a tool to support green universities development: assessment of the year 2011 ranking. J Clean Prod. 2013;61:46-53. DOI: 10.1016/j.jclepro.2013.02.034.

[4] Bekessy S, Samson K, Clarkson R. The failure of non-binding declarations to achieve university sustainability - a need for accountability. Int J Sust High Educ. 2007;8:301-16. DOI: $10.1108 / 14676370710817165$.

[5] Biasutti M, Frate S. A validity and reliability study of the attitudes toward sustainable development scale. Environ Educ Res. 2017;23(2):214-30. DOI: 10.1080/13504622.2016.1146660.

[6] Bartlett PF, Chase GW. Sustainability on Campus: Stories and Strategies for Change. Cambridge, Massachusetts: MIT Press; 2004. ISBN: 9780262524223.

[7] Creighton SH. Greening the Ivory Tower: Improving the Environmental Track Record of Universities, Colleges, and Other Institutions. Cambridge, Mass: MIT Press; 1998. ISBN: 9780262531511.

[8] Cioca LI, Ivascu L, Rada EC, Torretta V, Ionescu G. Sustainable development and technological impact on $\mathrm{CO}_{2}$ reducing conditions in Romania. Sustainability. 2015;7(2):1637-50. DOI: 10.3390/su7021637.

[9] Holdsworth S, Thomas IA. Sustainability education academic development framework (SEAD). Environ Educ Res. 2016;22(8):1073-97. DOI: 10.1080/13504622.2015.1029876.

[10] Jajo NK, Harrison J. World university ranking systems: an alternative approach using partial least squares path modelling. J Higher Educ Policy Manage. 2014;36(5):471-82. DOI: 10.1080/1360080X.2014.936090.

[11] Lauder A, Sari RF, Suwartha N, Tjahjono G. Critical review of a global campus sustainability ranking: GreenMetric. J Clean Prod. 2015;108:852-63. DOI: 10.1016/j.jclepro.2015.02.080.

[12] Lukman R, Kranjc D, Glavic P. University ranking using research, educational and environmental indicators. J Clean Prod. 2010;18:619-28. DOI: 10.1016/j.jclepro.2009.09.015. 
[13] Moed HF. Critical comparative analysis of five world university rankings. Scientometrics. 2016;1-24. DOI: 10.1007/s11192-016-2212-y.

[14] Scott R. Education for sustainability through a photography competition. Sustainability. 2015;6(2):474-86. DOI: $10.3390 / \mathrm{su} 6020474$.

[15] Handfield R, Walton SV, Sroufe R, Melnyk SA. Applying environmental criteria to supplier assessment: A study in the application of Analytical Hierarchy Process. European J Operational Res. 2002;141:70-87. DOI: 10.1016/S0377-2217(01)00261-2.

[16] Izunildo C, Antonio G, Virgilio CM. A decision-making model for lean, agile, resilient and green supply chain management. Int J Product Res. 2012;50(17):4830-45. DOI: 10.1080/00207543.2012.657970.

[17] Tsai SB, Huang CY, Wang CK, Chen Q. Using a mixed model to evaluate job satisfaction in high-tech industries. PLoS ONE. 2016;11(5):e0154071. DOI: 10.1371/journal.pone.0154071.

[18] Wu WW, Lee YT. Developing global managers' competencies using Fuzzy DEMATEL method. Expert Systems Applications. 2007;32(2):499-507. DOI: 10.1016/j.eswa.2005.12.005.

[19] Lin CJ, Wu WW. A causal analytical method for group decision making under fuzzy environment. Expert System Applications. 2008;34(1):205-13. DOI: 10.1016/j.eswa.2006.08.012.

[20] Lee YC, Hsieh YF. Integration of revised simultaneous importance performance analysis and decision making trial and evaluation laboratory - A study of mobile telecommunication industry in Taiwan. African J Business Manage. 2011;5(6):2312-21. Available from: https://www.researchgate.net/publication/299308104.

[21] Wu WW. Segmenting critical factors for successful knowledge management implementation using the fuzzy DEMATEL method. Appl Soft Computing. 2012;12(1):527-35. DOI: 10.1016/j.asoc.2011.08.008.

[22] Guo JJ, Tsai SB. Discussing and evaluating green supply chain suppliers: A case study of the printed circuit board industry in China. South African J Industrial Eng. 2015;26(2):56-67. DOI: 10.7166/26-2-956.

[23] Tsai SB, Wang K. Using a novel method to evaluate the performance of human resources in green logistics enterprises. Ecol Chem Eng S. 2019;26(4):629-40. DOI: 10.1515/eces-2019-0045. 